\title{
Hydrophilic Matrix Based Oral Controlled Release Tablets of Melt Sonocrystallized Simvastatin
}

\author{
Surendra Tripathy ${ }^{*}$, Brijesh Kumar Singh, Dilip Kumar Patel, Narahari Narayan Palei \\ Varanasi College of Pharmacy, Babatpur, Varanasi-221006, India.Department of Pharmaceutical Sciences, SHIATS, Allahabad, India. Sree Vidyanikethan \\ College of Pharmacy, Tirupati-517102, India.
}

\begin{tabular}{|c|c|}
\hline ARTICLE INFO & ABSTRACT \\
\hline Article history: & \multirow{10}{*}{$\begin{array}{l}\text { The major drawback of Simvastatin to formulate a dosage form is its poor aqueous solubility. In this study a } \\
\text { solvent and carrier less technique called Melt sonocrystallization was utilized to form tiny crystals of } \\
\text { Simvastatin with enhanced solubility in distilled water and Phosphate buffer pH 7.4, with an insignificant ( }>\text { > } \\
0.05 \text { ) change in partition behaviour. The Melt sonocrystallized Simvastatin (MSCSIM) was characterized by } \\
\text { FT-IR, DSC and SEM. The flow property was characterized and compared with pure Simvastatin. The } \\
\text { MSCSIM was incorporated in directly compressed matrix tablets formed with varying proportion of HPMC } \\
\text { K100 LV and starch. The formed tablets were evaluated for pharmacotechnical parameters along with drug } \\
\text { release study. After melt sonocrystallization the chemical integrity of drug was unchanged and showed a sound } \\
\text { flow property. The pharmacotechnical features of the tablets were noted to be within pharmacopoeial limit. The } \\
\text { formulation F5 displayed a comparatively more controlled release of drug }(96.45 \%) \text { over } 12 \text { hours. The major } \\
\text { release mechanism was found to be anomalous diffusion, with n value of } 0.58 \text { from the Korsmeyer-Peppas } \\
\text { model, suggesting the drug release driven by swelling of matrix and diffusion. This technique may prove to be } \\
\text { beneficial for poorly water soluble drugs and the melt sonocrystallized drugs can lend themselves for developing } \\
\text { controlled release formulations. }\end{array}$} \\
\hline Received on: $21 / 05 / 2016$ & \\
\hline Revised on: $15 / 07 / 2016$ & \\
\hline Accepted on: 14/08/2016 & \\
\hline Available online: 26/09/2016 & \\
\hline Key words: & \\
\hline Simvastatin, & \\
\hline Meltsonocrystallization, & \\
\hline Solubility, Matrix, Controlled & \\
\hline release. & \\
\hline
\end{tabular}

\section{INTRODUCTION}

Drugs having a fair solubility profile are supposed to be absorbed readily from the biological membrane. The drug which are not soluble in aqueous phases always show bioavailability problem. The drug Simvastatin (SIM), which is a poorly soluble drug, is thus selected for solubility enhancement, which is a 3hydroxy-3-methylglutary coenzyme A (HMG CoA) reductase inhibitor, the enzyme that catalyzes the conversion of HMG-CoA to mevalonate, the rate-limiting step in the biosynthesis of cholesterol. It is reported to be well absorbed from the GIT, so improvement of its solubility may prove to be an important

\footnotetext{
* Corresponding Author

Email:surendratripathy210@gmail.com
}

aspect to enhance its GI absorption and thereby, the bioavailability (Murtaza, 2012).

Several techniques have been developed by researchers to increase the solubility profile of SIM, which includes Inclusion complex formation technique (Varshosaz et al., 2011, Shiralasetti et al., 2010), Solid dispersion technique (Zhang et al., 2011), Solubilisation by surfactant (Margulis-Goshen et al., 2009, Meng et al., 2007), Milling technique (Zimper et al., 2010), Nanoprecipitation (Patil et al., 2011) etc. Few of these techniques require an additional carrier or solvent which is undesirable. So, a solvent and carrier free technique was selected for improving solubility of SIM i.e. the Melt sonocrystallization.

This technique has been reported by different researchers to improve solubility, micromeritic properties and rheological properties of drugs like Piroxicam (Gupta et al., 2013), Curcumin (Khan et al., 2015) etc. 
Attempts have been made by researchers to control the release of SIM by forming Hydrogels (Park et al., 2013), porous Polymer scaffolds (Gentile et al., 2016) and by formation of matrix tablets by using gums (Mantry et al., 2013).

For developing a controlled release tablet formulation of SIM, it was necessary to improve its solubility to some extent. In this present research, a humble attempt has been made to formulate the melt sonocrystals of SIM as matrix tablets by using Hydroxy propyl methylcellulose (HPMC) and starch as matrix forming polymer by direct compression method.

\section{MATERIALS AND METHODS}

Simvastatin (SIM) was kindly provided as a gift sample from Hetero Pharmaceuticals, Baddi, India. HPMC, Starch, Lactose, Magnesium stearate and PVP were obtained from S.D Fine Chemicals, Mumbai, India. Talc was purchased from $\mathrm{CDH}$ Pvt. Ltd., New Delhi, India.

\section{Preparation of Melt sonocrystallized Simvastatin (MSCSIM)}

The drug $(2 \mathrm{~g})$ was melted in a vessel on a paraffin oil bath maintained at $190{ }^{\circ} \mathrm{C}$. Molten mass was poured in a vessel containing $200 \mathrm{ml}$ of deionised water maintained at $80^{\circ} \mathrm{C}$ using thermostatic water bath and sonicated for 7 minutes using probe ultrasonicator (iksonic U 200 control) at amplitude of $80 \%$ and cycle of 0.8 per sec. The product obtained after solidification of dispersed droplet was separated by filtration by Whatmann filter paper and dried at room temperature. Yield was calculated after complete drying of the crystals (Gupta et al., 2015).

\section{Characterization of MSCSIM}

\section{Fourier-Transformed Infrared Spectroscopy}

FTIR spectra were obtained by using an FTIR spectrometer-430 (JASCO, Japan). The samples previously ground and mixed thoroughly with Potassium bromide (KBr), an infraredtransparent matrix, at 1:5 (sample to $\mathrm{KBr}$ ) ratio. The $\mathrm{KBr}$ discs were prepared by compressing the powders at a pressure of 5 tons for $5 \mathrm{~min}$ in a hydraulic press. Forty scans were obtained at a resolution of $4 \mathrm{~cm}^{-1}$, from 4,000 to $300 \mathrm{~cm}^{-1}$ (Paradkar et al., 2006, Deshmukh et al., 2013).

\section{Differential Scanning Calorimetry (DSC)}

The DSC measurements were performed on a DSC-6100 (Seiko Instruments, Japan) instrument with a thermal analyzer. All accurately weighed samples (SIM and MSCSIM) were placed in sealed Aluminum pans and DSC was run at a scanning rate of $10^{\circ} \mathrm{C} / \mathrm{min}$ from $25^{\circ} \mathrm{C}$ to $200^{\circ} \mathrm{C}$ under Nitrogen flow $(20 \mathrm{ml} / \mathrm{min})$ (Deshmukh et al., 2013).

\section{Scanning Electron Microscopy (SEM)}

SEM (LEO $435 \mathrm{VP}$, UK) was used to determine the morphology of pure SIM and MSCSIM. Samples were fixed on support with carbon glue and coated with gold using gold sputter model in a high vacuum evaporator. Samples were then subjected for viewing the surface with scanning electron microscopy (Gupta et al., 2013).

\section{Comparative Saturation Solubility study of SIM and MSCSIM}

An excess amount of SIM and MSCSIM were added separately to different solvent systems like water and phosphate buffer 7.4 and the samples were shaken continuously in a mechanical shaker for 48 hours at $37{ }^{\circ} \mathrm{C}$ until equilibrium was achieved. After 48 hours the solution was filtered through nylon filter paper. The filtrate was diluted suitably with the respective solvent system and the amount was quantified spectrophotometrically (Chaudhary and Uttekar, 2009).

\section{Comparative partition coefficient study of SIM and MSCSIM}

The partition coefficient of SIM and MSCSIM were measured between distilled water and n-Octanol system and phosphate buffer $\mathrm{pH} 7.4$ and n-Octanol system (each medium $10 \mathrm{ml}$ ) at an ambient temperature of $37^{\circ} \mathrm{C}$ in different separating funnels. The funnels with both the phases were shaken for 4 hours gently and then kept for $24 \mathrm{~h}$ for achieving mutual separation. After achieving the equilibrium between the aqueous and organic phase, the phases were separated from each other and SIM and MSCSIM were added to the aqueous phase of respective funnels. Both the phases were again mixed and shaken gently for 4 hours and kept for 48 hours to attain the equilibrium. $1 \mathrm{ml}$ of the aqueous phase drug solution was taken separately from each funnel, diluted suitably and quantified spectrophotometrically. Partition coefficient was measured by using the formula (Tripathy and Das, 2013, Gupta et al, 2013);

$$
\mathrm{P}=\left(\mathrm{C}_{\mathrm{a}}-\mathrm{C}_{\mathrm{b}}\right) / \mathrm{C}_{\mathrm{b}}
$$

Where, $\mathrm{P}=$ Partition coefficient, $\mathrm{C}_{\mathrm{a}}=$ Initial concentration of drug in aqueous phase $(\mu \mathrm{g} / \mathrm{ml})$ and $\mathrm{C}_{\mathrm{b}}=$ Final concentration of drug in aqueous phase after equilibrium $(\mu \mathrm{g} / \mathrm{ml})$

\section{Flow property study}

SIM and MSCSIM forms were characterized for bulk density, tapped density, Carr's compressibility index, angle of repose and Hausner's ratio. Dynamic angle of repose of SIM and MSCSIM was determined by method reported by Gupta et al., where by placing $1 \mathrm{~g}$ of drug powder in a lab fabricated rotating cylinder apparatus and allowed to rotate at $25 \mathrm{rpm}$ for $5 \mathrm{~min}$. The angle made by the bulk of the drug powder against the horizontal tangent was recorded and dynamic angle of repose for each sample was calculated. The bulk density was obtained by dividing the weight of sample by the final volume in $\mathrm{cm}^{3}$ of the sample in the cylinder. Hausner's ratio was determined by dividing the tapped density by bulk density (Dhumal et al., 2009, El- Kamel et al., 2008). The percent compressibility index was calculated by using the equation:

$\%$ Compressibility Index $=($ Tapped density - Bulk density)/Tapped density $\times 100$ 


\section{Preparation of Matrix based Tablets of MSCSIM}

Composition containing 40mg MSCSIM were prepared by direct compression technique using single punch tablet machine (10 $\mathrm{mm}$ die diameter). HPMC (K100 LV) was selected for the formulation as it has been reported to form good matrix. Starch acts as a release rate controller, as well as the moisture content of starch helps in binding the tablet. Polyvinylpyrrolidone (PVP) was used to improve cohesiveness of the powders by providing binding action. Nine formulations F1 -F9 has been prepared by varying the ratio of HPMC and Starch (Gawali et al, 2012, Cao et al., 2005, Fuhrer, 1999). The formulation F9 (not tabulated) contains the same ingredients except that starch was absent in it. The composition of formulations is given in Table 1.

Table 1: Composition of Tablet formulations.

\begin{tabular}{lcccccccc}
\hline Ingredients & F1 & F2 & F3 & F4 & F5 & F6 & F7 & F8 \\
\hline MSCSIM & 40 & 40 & 40 & 40 & 40 & 40 & 40 & 40 \\
HPMC : Starch & $1: 9$ & $1: 5$ & $1: 4$ & $1: 3$ & $1: 1$ & $1: 2$ & $1: 4$ & $1: 8$ \\
PVP (\%) & 2 & 2 & 2 & 2 & 2 & 2 & 2 & 2 \\
MgStearate $(\%)$ & 2 & 2 & 2 & 2 & 2 & 2 & 2 & 2 \\
Talc (\%) & 2 & 2 & 2 & 2 & 2 & 2 & 2 & 2 \\
\hline
\end{tabular}

\section{Pharmacotechnical Characterization of Tablets}

The prepared matrix tablets were evaluated for tablet thickness, hardness, friability, disintegration time, \% weight variation, \% Drug content and in vitro release. A Vernier calliper (least count $=0.01$ ) was used to determine thickness of 10 randomly selected tablets. The result was expressed as mean values $\pm \mathrm{SD}$. The hardness of the tablets was determined using Monsanto hardness tester (HICON, Grover Enterprises, New Delhi, India), as expressed in $\mathrm{kg} / \mathrm{cm}$. Three tablets were randomly picked from each formulation. Friability of prepared tablets was determined by using Roche friabilator (HICON friability test apparatus). Ten tablets from each batch were selected randomly followed by accurate weighing. Tablets were then placed in plastic chamber that rotates at $25 \mathrm{rpm}$, dropping tablets from a distance of six inches with each revolution. The friabilator was operated for 100 revolutions and the tablets were made dust free and reweighed (Mantry et al., 2013, Bhise et al., 2014). Friability was calculated using following equation:

$\%$ Friability $=[($ Initial weight - Final weight $) /$ Initial weight $] \times 100$

For weight variation test, twenty tablets of each batch were selected randomly and weighed. The average weight was calculated. The tablets were passed the test if the individual weight of not more than 2 tablets deviated from the average weight by more than the percentage as per pharmacopoeial limits and none deviated more than twice the percentage.

\section{In Vitro Drug Release}

The prepared tablets incorporated with MSCSIM were evaluated for drug release study. To study In vitro dissolution of formulations, USP dissolution apparatus: Type-I was used with
Phosphate buffer with $\mathrm{pH} 7.4$ as the Dissolution medium at a temperature of $37 \pm 0.5^{\circ} \mathrm{C}$ with a basket Rpm of 50. Sample of 5 $\mathrm{ml}$, was withdrawn at regular intervals. The volume withdrawn was replaced by fresh volume of dissolution medium to maintain constant volume and sink condition of dissolution medium. The samples were filtered through whatman filter paper and analyzed spectro-photometrically at $238.90 \mathrm{~nm}$. The amount of drug released was determined using calibration curves. Dissolution studies for each formulation were performed in triplicates (Kavanagh et al., 2014).

\section{Statistical Analysis}

The data obtained in this study have been expressed as Mean \pm S.D (Standard Deviation). The data were subjected to statistical analysis and assessed by one way Analysis of Variance (ANOVA) following Dunnett's $t$ - test. $p$ value of less than 0.05 was considered as evidence of a significant difference.

\section{RESULTS AND DISCUSSION}

Melt sonocrystallized Simvastatin (MSCSIM) particles were generated from the pure powder form of Simvastatin (SIM). MSCSIM preparation involved a two step process which involves preparation of molten magma and application of ultrasonic energy to the magma after pouring it to the aqueous phase. The above two steps leads to formation of solidified particles with strong bonds which again helps the particles to resist the shear produced during the sonication. Upon the addition of molten SIM, it slowly reached the bottom due to its viscous nature and started solidifying loosely itself. Applying the ultrasonic energy to the loosely solidified melt, it resulted in its fragmentation and formation of tiny crystalline particles which was throughout the aqueous phase. The sonication energy was probably sufficient to fragment the loose solid and induce kinetic movement of the fragments. Due to this movement of the tiny fragments all over the aqueous medium, all fragments got rapidly crystallized into fine particles and dispersed (Khan et al., 2015, Gupta et al., 2013). The optimized temperature and sonication time were $80^{\circ} \mathrm{C}$ and 7 minutes respectively. This condition was enough for the formation of filterable particles. Sonication for a longer time was avoided as it may induce further aggregation of particles to form large particles. The yield was calculated to be $92.2 \%$.

\section{Characterization of MSCSIM}

\section{Fourier-Transform Infrared Spectroscopy}

The FT-IR study was performed to detect any chemical change aroused during the melt sonocrystallization. The spectra (Fig.1) of both the sample i.e., the SIM and MSCSIM were found superimposable to each other. The peaks of major characteristic functional groups were retained. The major peaks identified were at $1704.2 \mathrm{~cm}^{-1}(\mathrm{C}=\mathrm{O}$ stretching $), 1624.05$ and $1446.6 \mathrm{~cm}^{-1}$ (Aromatic $\mathrm{C}=\mathrm{C}$ stretching), $3650 \mathrm{~cm}^{-1}$ (Free $\mathrm{O}-\mathrm{H}$ stretching, aromatic) and $804.62 \mathrm{~cm}^{-1}$ (Aromatic $\mathrm{C}-\mathrm{H}$ out of plane bending). 
This suggested that no chemical change has occurred after the crystallization from a molten mass by using ultrasonic energy.

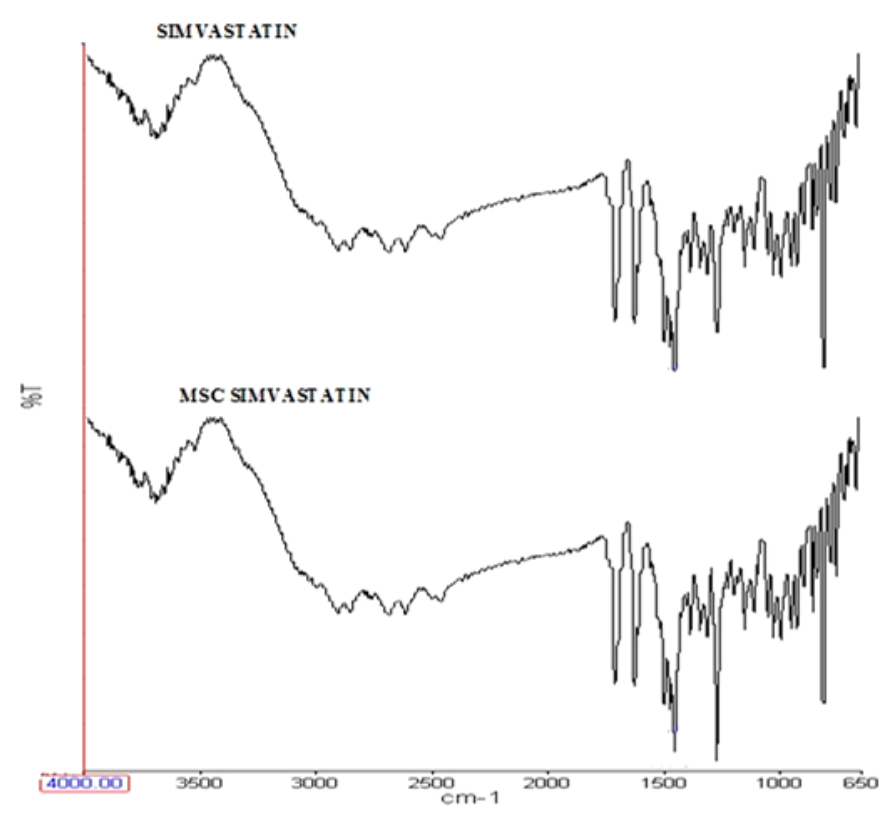

Fig. 1: FT-IR Spectra of SIM and MSCSIM.

\section{Differential Scanning Calorimetry}

Though, the FT-IR had already revealed that there was no chemical alteration during the crystallization, the DSC study was performed to consolidate the fact that no such chemical change has occurred in the drug after melt sonocrystallization.

The thermogram of SIM (Fig.2a) showed a single endothermic peak at $139.41^{\circ} \mathrm{C}$, with a normalized energy of 65.09 $\mathrm{J} / \mathrm{g}$. On the other hand the thermogram of the MSCSIM (Fig.2b) didn't show any significant pattern. However, the peak was found at $140.06^{\circ} \mathrm{C}$, with a normalized energy of $67.01 \mathrm{~J} / \mathrm{g}$, indicating that both the samples behaved identically to the thermal procedure. No peak broadening or asymmetry were detected, which may be due to uniform crystal structures (Deshmukh et al., 2013). Further, no sign of any change in the drug was observed comparing both the thermograms.

\section{Scanning Electron Microscopy}

The photomicrographs were studied to generate some idea on the morphological behaviour of the SIM and MSCSIM, from which the change in crystal behaviour can be observed. The micrograph of SIM (Fig.3 A) revealed that the original SIM exhibited some agglomeration with planar surface and close view to a particular crystal shows itself as a little elongated shaped, which is characteristic to the conventional crystals.

The micrograph of MSCSIM (Fig.3 B) has got finer and visually distinguished elongated shape. The short term cavity formed in the crystallization medium due to the ultrasonic wave causes zones of different pressure and temperature, inducing the formation of nuclei and further crystal growth (Gupta et al., 2013, Paradkar et al., 2006).

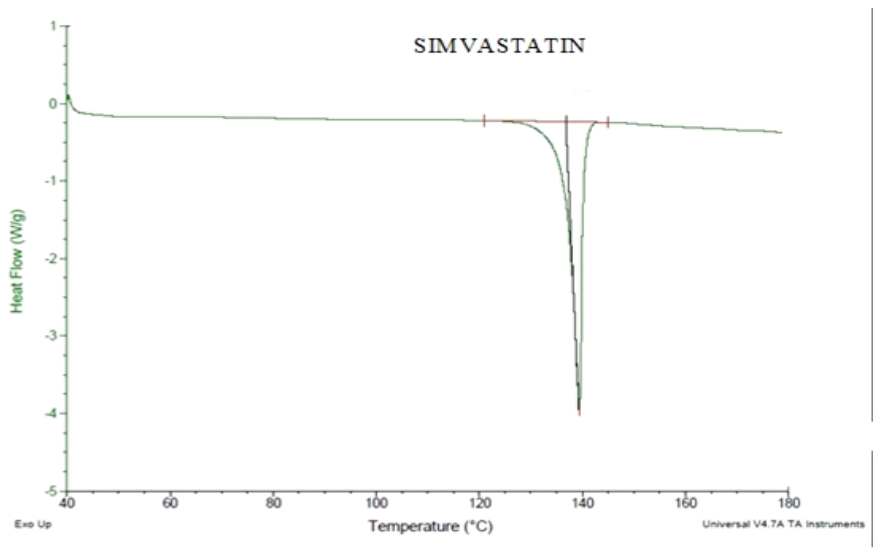

Fig. 2(a): Thermogram of pure SIM

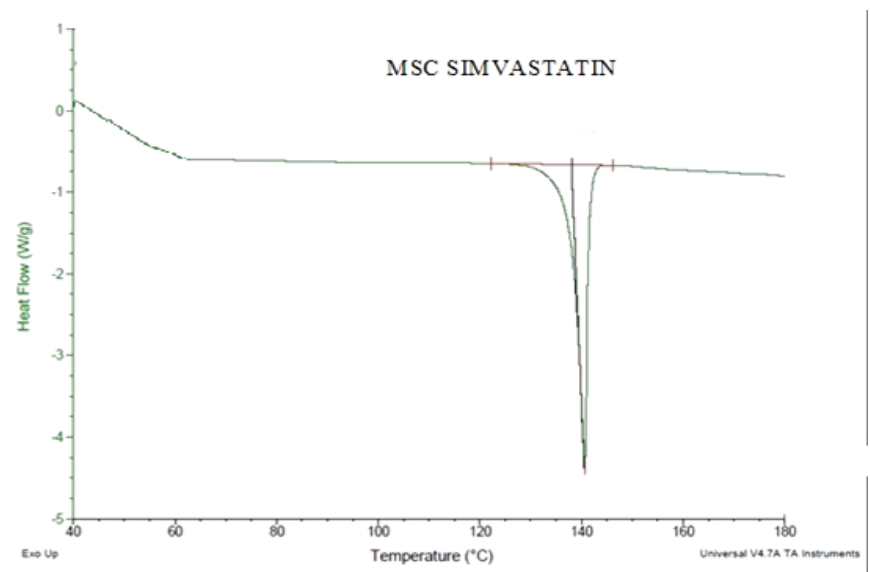

Fig. 2(b): Thermograms of MSCSIM
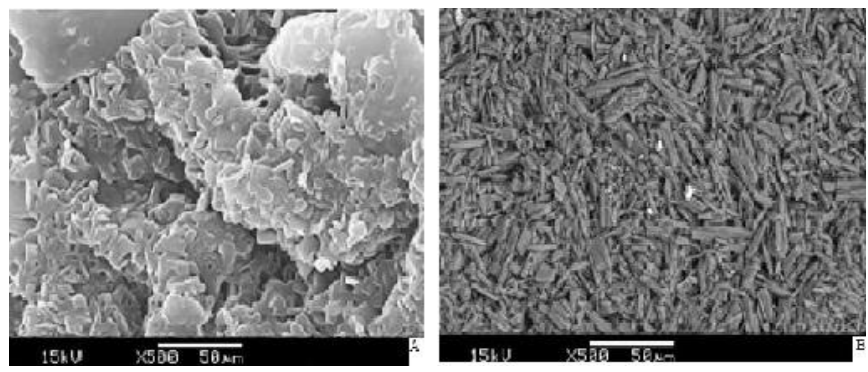

Fig. 3: Photomicrographs of SIM (A) and MSCSIM (B).

\section{Comparative Saturation Solubility study of SIM and MSCSIM}

After melt sonocrystallization SIM was found to have increased solubility in both water as well as phosphate buffer $\mathrm{pH}$ 7.4 (Table 2). The enhancement of solubility value in distilled water was 2.16 fold and that in Phosphate buffer $\mathrm{pH} 7.4$ was 2.85 fold. This enhancement in solubility can be attributed to the formation more regular small sized crystal upon meltsonocrystallization. The crystals might have got more surface 
area for solubilization. Simvastatin is weakly acidic drug and showed enhanced solubility in alkaline medium. The MSCSIM showed more improvement in solubility in alkaline media (Jagtap et al., 2014).

Table 2: Comparative solubility study of Pure Simvastatin and MSC Simvastatin.

\begin{tabular}{lll}
\hline Solvent & Pure Simvastatin & MSC Simvastatin \\
\hline Distilled Water & $1.613 \mu \mathrm{g} / \mathrm{ml}$ & $3.485 \mu \mathrm{g} / \mathrm{ml}$ \\
Phosphate buffer pH 7.4 & $24.045 \mu \mathrm{g} / \mathrm{ml}$ & $68.561 \mu \mathrm{g} / \mathrm{ml}$ \\
\hline
\end{tabular}

\section{Comparative partition coefficient study of SIM and MSCSIM}

Simvastatin is BCS class-II drug. Enhancement in aqueous solubility of the drug after melt sonocrystallization should not affect the partition behaviour of the drug. The comparative partition coefficient study revealed that the drug showed an insignificant change in the partition property, which indicated that the drug can be incorporated in any formulation and the drug permeation will not be affected (Gupta et al., 2013) (Table 3).

Table 3: Comparative partition coefficient study of Pure Simvastatin and MSC Simvastatin.

\begin{tabular}{lcc}
\hline \multirow{2}{*}{ Drug } & $\begin{array}{c}\text { Distilled Water: } \mathbf{n -} \\
\text { Octanol (10:10) }\end{array}$ & $\begin{array}{c}\text { Phosphate buffer } \mathbf{~ p H} \\
\mathbf{7 . 4 : n - o c t a n o l ~ ( 1 0 : 1 0 )} \\
\mathbf{K}_{\mathbf{O} / \mathbf{W}}\end{array}$ \\
\hline Pure Simvastatin & 4.31 & 4.16 \\
MSC Simvastatin & 4.08 & 4.01 \\
\hline
\end{tabular}

\section{Comparative Flow Property study}

The data obtained from the rheological study of both SIM and MSCSIM, it was clear that the MSCSIM possessed better flow property than the SIM (Table 4). The particle friction and interparticular contact may reduce the flow ability of any powder. The reduction in size and formation of more uniform crystals with smooth surface might have imparted the fine flow property to MSCSIM. Also, a few fines were produced during crystallization which took the void space and increased the density. However, the parameters considered for flow property indicated a better flow of MSCSIM. An increase in $26.08 \%$ and $16.94 \%$ in Bulk density and Tapped density has been observed respectively. The Carr's index value of MSCSIM was calculated to be 15.94, which is considered to be good flow, as compared to the pure SIM. Both the dynamic and static angle of repose value for the MSCSIM also suggested a good flow property. The MSCSIM can be referred as a noncohesive bulk material having a sound flow property (ElKamal et al., 2008).

\section{Evaluation of Matrix Tablets}

The sound flow behaviour of the MSCSIM encouraged the formation of tablets by direct compression methods (Table 5). The thickness values of tablets were found to be in precision. The hardness range of tablets was 7.9-8.4 Kg/cm, which can withstand the jerks during shipment or handling. Mechanical stability of the tablets was confirmed from the friability values, which was below $1 \%$. The tablet weight variation was within the pharmacopoeial limit. The \% Drug content range was 94.87- 101.12, which was also within the Pharmacopoeial limit according to I.P., 1996.

Table 4: Comparative study of parameters for characterization of flow property.

\begin{tabular}{lll}
\hline Parameters & \multicolumn{1}{c}{$\begin{array}{c}\text { SIM } \\
(\text { Value } \pm \text { S.D) }\end{array}$} & $\begin{array}{c}\text { MSCSIM } \\
(\text { Value } \pm \text { S.D) }\end{array}$ \\
\hline Bulk density $\left(\mathrm{g} / \mathrm{cm}^{3}\right)$ & $0.46 \pm 0.07$ & $0.58 \pm 0.18$ \\
Tapped density $\left(\mathrm{g} / \mathrm{cm}^{3}\right)$ & $0.59 \pm 0.12$ & $0.69 \pm 0.17$ \\
Carr's Index & 22.03 & 15.94 \\
Hausner Ratio & 1.28 & 1.18 \\
Dynamic angle of repose & $47.72 \pm 1.27$ & $33.18 \pm 1.84$ \\
Static angle of repose & $47.86 \pm 1.33$ & $33.07 \pm 1.07$ \\
\hline
\end{tabular}

S.D = Standard Deviation.

Table 5: Comparative evaluation of Pharmacotechnical parameters of prepared batches.

\begin{tabular}{ccccc}
\hline \multirow{2}{*}{ Parameters } & \multicolumn{4}{c}{ Formulations } \\
\cline { 2 - 5 } & F1 & F2 & F3 & F4 \\
\hline Thickness (mm) & $7.1 \pm 0.11$ & $7.2 \pm 0.05$ & $7.1 \pm 0.23$ & $7.4 \pm 0.18$ \\
Hardness $(\mathrm{Kg} / \mathrm{cm})$ & $8.1 \pm 0.3$ & $8.2 \pm 0.2$ & $8.1 \pm 0.4$ & $8.4 \pm 0.4$ \\
Wt. Variation(\%) & 6.24 & 6.76 & 8.13 & 7.46 \\
Friability (\%) & 0.66 & 0.71 & 0.62 & 0.59 \\
Disint.time (min.) & 150 & 155 & 164 & 168 \\
\% Drug Content & 95.24 & 94.87 & 98.33 & 101.12 \\
\hline F5 & $\mathbf{F 6}$ & $\mathbf{F 7}$ & $\mathbf{F 8}$ & $\mathbf{F 9}$ \\
\hline $7.2 \pm 0.08$ & $7.2 \pm 0.16$ & $7.4 \pm 0.31$ & $7.1 \pm 0.09$ & $7.2 \pm 0.23$ \\
$8.4 \pm 0.3$ & $8.3 \pm 0.2$ & $8.2 \pm 0.3$ & $8.0 \pm 0.3$ & $7.9 \pm 0.2$ \\
8.36 & 8.21 & 7.55 & 4.68 & 7.04 \\
0.45 & 0.51 & 0.59 & 0.68 & 0.78 \\
172 & 170 & 171 & 168 & 152 \\
99.19 & 97.35 & 95.75 & 98.29 & 99.08 \\
\hline
\end{tabular}

(Values \pm Standard Deviation).

\section{Evaluation of drug release kinetics}

In vitro dissolution studies were conducted on tablets of each of the formulations $\left(\mathrm{F}_{1}-\mathrm{F}_{9}\right)$. The $\%$ cumulative drug release of Simvastatin released at different time intervals were plotted. It was observed that the formulations F3, F4, F5 and F6 followed zero order, Higuchi model and Korsmeyer-Peppas model release kinetics by considering the linear portion of the graph from origin.

Formulations F1, F2, F7, F8 could not manage to control the release for 12 hours and released around $40 \%$ of drug in the first hour, which was not the motto of the work and undesirable (Gawali et al., 2012).

The higher percentage of HPMC (K 100 LV) and low content of starch in these formulations may have eroded quickly due to less viscosity of HPMC. The 1:1 ratio of HPMC and Starch (F5) was found to have better control over the drug release and showed a higher percentage $(96.45 \%)$ cumulative drug release after 12 hours among the rest formulations (Fig. 4a, 4b). The drug release kinetic modelling of F5 revealed that the formulation best fit the Higuchi model, followed by Korsmeyer-Peppas model which was followed by Zero order, respectively (Table 6). 


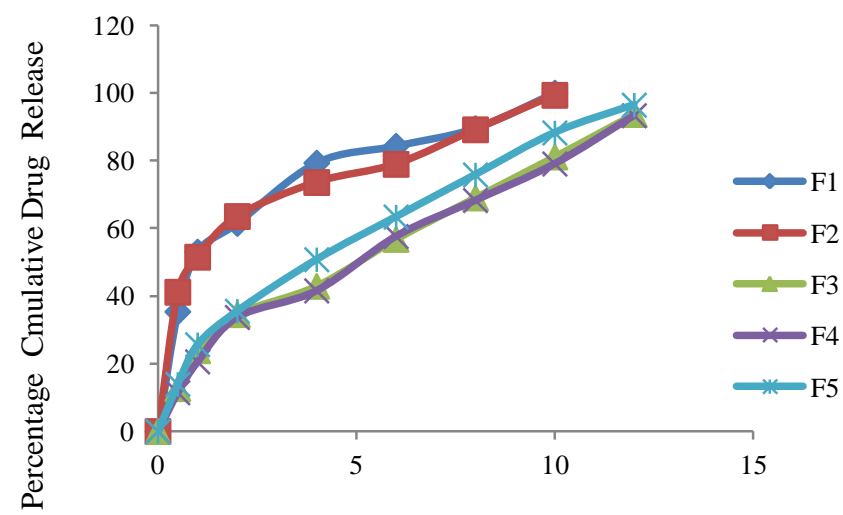

Time (hour)

Fig. 4a: Zero order drug release plots of formulation F1-F5.

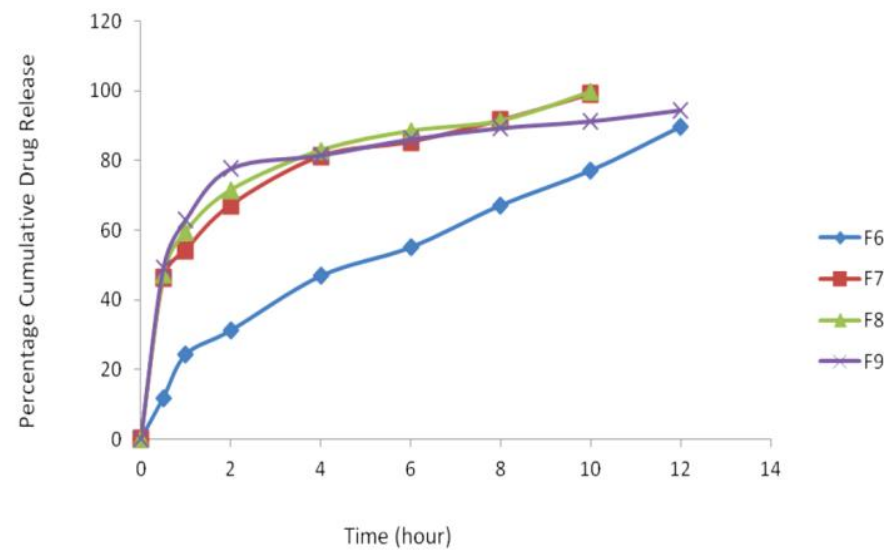

Fig. 4b: Zero order drug release plots of formulation F6-F9.

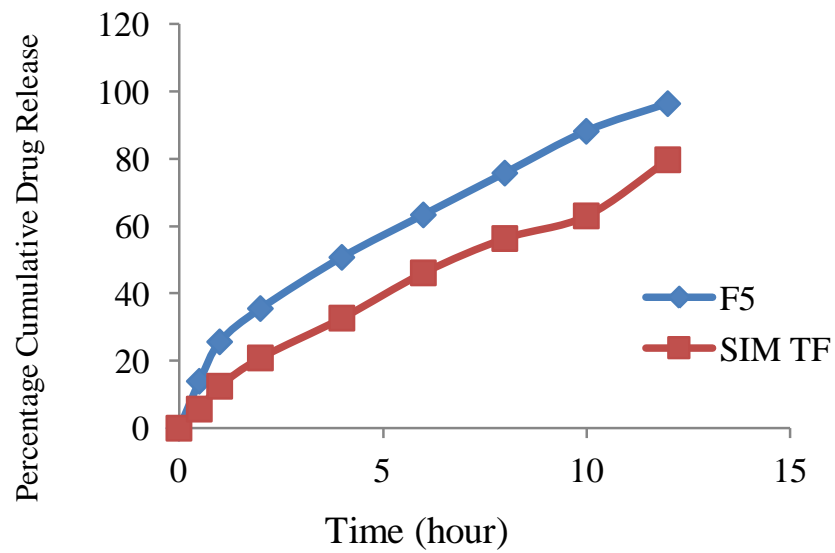

Fig. 4c: Zero order drug release plots of formulation F5 and SIM TF.

Table 6: Drug release kinetics modelling of F5.

\begin{tabular}{cccccc}
\hline Formulation & Zero order & $\mathbf{R}^{2}$ & First Order & $\mathbf{R}^{2}$ \\
\hline F5 & $\mathrm{Y}=7.832 \mathrm{X}+10.588$ & 0.977 & $\mathrm{Y}=0.062 \mathrm{X}+1.338$ & 0.844 \\
\hline Higuchi model & $\mathbf{R}^{2}$ & Korsmeyer-Peppas Model & $\mathbf{R}^{2}$ & $\mathbf{n}$ \\
\hline $\mathrm{Y}=28.27-3.508$ & 0.995 & $\mathrm{Y}=0.582 \mathrm{X}-0.625$ & 0.992 & 0.58 \\
\hline
\end{tabular}

This suggested that the major drug diffusion mechanism was by polymer swelling and erosion of polymer (Henrist et al., 1999). The $n$ value obtained from the Korsmeyer-Peppas model was found to be 0.58 , which corresponds to anamolous or NonFickian diffusion drug release mechanism, in which the process is driven by both swelling of matrix and diffusion of drug (Kavanagh et al., 2004, Sriamornsak et al., 2007, Carbinatto et al., 2014, Akhgari et al., 2011). The composition of formulation F5 was used to prepare another batch of formulation containing pure SIM and named as Simvastatin test formulation (SIM TF), to compare the $\%$ Cumulative drug release behaviour, which was found inferior to the F5 in terms of cumulative drug release, where after 8 hours a steep increase was felt which might have corresponded to the rapid erosion of remaining polymer in the formulation and insufficient starch left to control the release (Spiepmann and Peppas, 2001) (Fig. 4c).

\section{CONCLUSION}

Simvastatin, a BCS Class-II drug was successfully formulated as a matrix tablet, with the help of HPMC and Starch. The poor solubility profile of the drug was seen to have improved after the melt sonocrystallization process, without significant interference with the partition behaviour. This particular technique also improved the flow property of the simvastatin by reducing the cohesiveness. One of the most advantageous features of this technique is that, it does not involve any harmful solvents for designing the particles. Such class of drug, which frequently fails to lend itself for development of novel dosage forms due to solubility issues can be tested for melt sonocrystallization, which hopefully create a new area of formulation development by using this particle engineering technique. 


\section{ACKNOWLEDGEMENT}

The authors are highly thankful to the College authority for providing the research atmosphere as well as supplying the necessary materials for conducting this work.

\section{Financial support and sponsorship: Nil.}

Conflicts of interest: There are no conflicts of interest.

\section{REFERENCES}

Akhgari A, Abbaspour MR, Rezaee S, Kuchak A. Evaluation of the swelling, Erosion and drug release from polysaccharide matrix tablets based on pectin and Inulin. Jundishpur J Nat Pharm Prod, 2011; 6(1): 5158.

Bhise MR, Mohod SP, Narkhede MB, Sapkal SB. HPMC based Extended release Matrix tablet of Gabapentin by Direct compression Method. Turk J Pharm Sci, 2014; 11(1): 45-54.

Cao Y, Huang L, Chen J, Liang J, Long S, Lu Y. Development of a controlled release formulation based on a starch matrix system. Int $\mathbf{J}$ Pharm, 2005; 298(1): 108-16.

Carbinatto FM, Castro AD, Evangelista RC, Cury BSF. Insights into the swelling process and drug release mechanisms from cross-linked pectin/high amylase starch matrices. Asian J Pharm Sci, 2014; 9: 27-34.

Chaudhary PD, Uttekar PS. Meltsonocrystallization: a novel particle engineering technique for solubility enhancement. Int J Pharm Tech Res, 2009; 1(1): 111-20.

Deshmukh V, Deshmukh T, Deshmukh M, Jadhav P. Design and development of melt sonocrystallization technique for carbamazepine. Ind J Pharm Edu Res, 2013; 47: 199-205.

Dhumal RS, Biradar SV, Paradkar AR, York P. Particle engineering using sonocrystallization: salbutamol sulphate for pulmonary delivery. Int J Pharm 2009; 368: 129-37.

El-Kamel AH. Improvement of physicochemical and biopharmaceutical properties of flurbiprofen using melt sonocrystallization technique. Drug Dev Res, 2008; 69:34-41.

Fuhrer C. 1996. Inter-particulate attraction mechanisms. In: Aldernborn G, Nystro MC, ed. Pharmaceutical powder compaction technology. New York: Marcel Dekker 1-15.

Gawali P, Gupta A, Kachare S, Kshirsagar S. Formulation and evaluation of Matrix based sustained release tablets of Quetapine fumarate and influence of excipients on drug release. J Chem Pharm Res., 2012; 4(6): 3073-3081.

Gentile P, Nandagiri VK, Daly J, Chiono V, Mattu C, TondaTuro C, Ciardelli G, Ramtoola Z. Localised controlled release of Simvastatin from porous Chitosan-gelatin Scaffolds engrafted with Simvastatin loaded PLGA-Microparticles for bone tissue engineering application. Mat Sci Eng, 2016; 59:249-257.

Gupta PS, Sharma V, Pathak K. Melt sonocrystallized piroxicam for oral delivery: particle characterization, solid state analysis and pharmacokinetics. Expert Opin Drug Deliv, 2013; 10:17-32.

Henrist D, Lefebvre RA, Remon JP. Bioavailability of starch based hot stage extrusion formulations. Int J Pharm, 1999; 187(2): 18591.

Jagtap VA, Vidyasagar G, Dvivedi SC. Solubility enhancement of rosiglitazone by using melt sonocrystallization techniques. J Ultrasound, 2014; 17: 27-32.

Kavanagh N, Corrigan OI. Swelling and erosion properties of Hydroxyproprylmethylcellulose (Hypromellose) matrices-influence of agitation rate and dissolution medium composition. Int J Pharm, 2004; 279 (1-2):141-152.

Khan MA, Akhtar N, Sharma V, Pathak K. Product development studies on melt sonocrystallized curcumin for the treatment of Gastric cancer. Pharmaceutics, 2015; 7: 43-63.
Maheshwari A, Harshal J, Paradkar A. Melt sonocrystallization of ibuprofen: effect on crystal properties. Eur J Pharm Sci, 2005; 25:41-8.

Mantry S, Reddy KVN, Sriram N, Sahoo CS. Formulaion development and characterization of Sustained release matrix tablet of Simvastatin using Natural polymers. Indo-American J Pharm Res, 2013, 3(5): 4031-4041.

Margulis-Goshen K, Magdassi S. Formation of Simvastatin nanoparticles from microemulsion. Nanomed, 2009; 5(3): 274-281.

Meng J, Zheng L. Application of mixture experimental design to simvastatin apparent solubility prediction in the microemulsion formed by self-microemulsifying. Drug Dev Ind Pharm, 2007; 33(9): 927-931.

Murtaza G. Solubility enhancement of Simvastatin: A Review. Acta Pol Pharm Drug Res, 2012; 69(4): 581-590.

Paradkar A, Maheshwari M, Kamble R, Grimsey I, York P. Design and evaluation of celecoxib porous particles using melt sonocrystallization. Pharm Res, 2006; 23(6):1395-1400.

Park YS, Davis AE, Park KM, Lin Cy, Than KD, Lee K, Park JB, Jo I, Park KD, Yang VC. Controlled release of Simvastasin from In Situ forming hydrogel triggers bone formation in MC3T3-E1 Cells. APPS J, 2013; 15(2): 367-76.

Patil MS, Bavaskar KR, Girnar GA, Jain AS, Tekade AR. Preparation and optimization of simvastatin nanoparticles for solubility enhancement and in vivo study. Int J Pharma Res Dev, 2011; 2(12): 219 226.

Shiralashetti S, Patil A, Patil J. Influence of method of preparation on solubility, physicochemical properties and in vitro release profile of Simvastatin-Cyclodextrin inclusion complexes: A comparative study. Int J Chem Tech Res, 2010; 2(1): 562-571.

Spiepmann J, Peppas NA. Modelling of Drug Release from Delivery Systems Based on Hydroxypropyl Methylcellulose (HPMC). Adv Drug Deliv Rev, 2001; 48: 139-157.

Sriamornsak P, Thirawong N, Korkerd K. Swelling, erosion and release behaviour of alginate-based matrix tablets. Eur J Pharm Biopharm, 2007; 66(3): 435-450.

Tripathi R, Biradar SV, Mishra B, Paradkar AR. Study of polymorphs of progesterone by novel melt sonocrystallization technique: a technical note. AAPS Pharm Sci Tech 2010; 11:1493-1498.

Tripathy S, Das MK. Curcumin-Phospholipid Supramolecular complex for transdermal application. Der Pharm Lett, 2013; 5(5):224-233.

Varshosaz J, Tavakoli N, Salamat FA. Enhanced dissolution rate of Simvastatin using spherical crystallization technique. Pharm Dev Technol, 2011; 16 (5): 529-535.

Zhang Y, Zhang J, Jiang T, Wang S. Inclusion of the poorly water soluble drug simvastatin in mesocellular foam nanoparticles: drug loading and release properties. Int J Pharm, 2011; 410 (1-2): 118-124.

Zimper U, Aaltonen J, Krauel-Goellner K, Gordon KC, Strachan CJ, Rades T. The influence of milling on the dissolution performance of Simvastatin. Pharmaceutics, 2010; 2(4): 419-431.

\section{How to cite this article:}

Tripathy S, Singh BK, Patel DK, Palei NN. Hydrophilic Matrix Based Oral Controlled Release Tablets of Melt Sonocrystallized Simvastatin. J App Pharm Sci, 2016; 6 (09): 041-047. 